\title{
The impact of chronic low back pain on leisure participation: implications for occupational therapy
}

\author{
Samantha Ashby, ${ }^{1}$ Maureen Fitzgerald ${ }^{2}$ and Simon Raine ${ }^{3}$
}

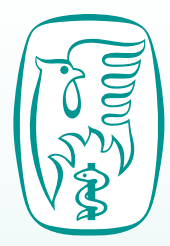

Key words:

Leisure participation, chronic low back pain, occupational therapy.

${ }^{1}$ Lecturer in Occupational Therapy, School of Health Sciences, Faculty of Health, University of Newcastle, Callaghan, New South Wales, Australia.

${ }^{2}$ Medical Anthropologist, formerly at the University of Sydney, Lidcombe, New South Wales, Australia.

${ }^{3}$ Therapy Unit Manager, Karana Therapy Unit, Lingard Private Hospital, Merewether, New South Wales, Australia.

Corresponding author: Samantha Ashby, Lecturer in Occupational Therapy, School of Health Sciences, Faculty of Health, University of Newcastle, University Drive, Callaghan, New South Wales 2308, Australia. Email: samantha.ashby@newcastle.edu.au

Reference: Ashby S, Fitzgerald M, Raine $S$ (2012) The impact of chronic low back pain on leisure participation: implications for occupational therapy. British Journal of Occupational Therapy, 75(11), 503-508.

DOI: $10.4276 / 030802212 \times 13522194759897$

(C) The College of Occupational Therapists Ltd. Submitted: 29 November 2011.

Accepted: 17 April 2012.
Aim: Chronic low back pain can reduce engagement and participation in all areas of daily life. Previous research has focused on employment and vocational rehabilitation initiatives, with less attention paid to its impact on leisure. This paper examines the difficulties men with chronic low back pain experienced in the maintenance of their leisure activities. It explores the connection between leisure and social networks and the potential barriers to resuming leisure occupations due to chronic low back pain.

Method: This ethnographic study examined the experiences of 11 men involved in a vocational rehabilitation programme in New South Wales, Australia. Data were gathered using participant observation and semi-structured interviews.

Findings: Chronic low back pain has a critical impact on leisure occupations. It creates two barriers to a client's engagement in former leisure occupations: physical restrictions and financial barriers.

Conclusion: The findings build on knowledge of how leisure impacts on social dimensions of health and wellbeing. Occupational therapists can play an important role in enabling people with chronic low back pain to re-engage in leisure. These interventions may reduce the social isolation experienced by individuals due to the loss of leisure activity.

\section{Introduction}

A core aim of occupational therapy is the enablement of meaningful occupation to promote health and a sense of wellbeing (Rebeiro and Polgar 1999). In the language of this unique professional domain, occupation is defined as meaningful by the client and can include 'chunks of activity that can be named in the lexicon of the culture' in which the person lives (Zemke and Clark 1996, pvii). Most theorists identify three main occupational areas: self-care, productivity and leisure, with Chapparo and Ranka (1997) including rest as a fourth area. However, there is an increased recognition that these classifications are problematic and that occupational therapists increasingly deal with how occupation is subjectively experienced by individuals (Hammell 2009).

\section{Literature review}

\section{Low back pain}

For occupational therapists who work in vocational rehabilitation, one of the most common and disabling conditions for clients is chronic low back pain (Picavet et al 2002). Although its influence on self-care and productivity has received considerable attention, less is paid to its impact on leisure participation. Low back pain is one of the most common ailments in modern societies, affecting $10 \%$ to $15 \%$ of the Australian population, which is a similar percentage to that in the United States and the United Kingdom (De Souza and Frank 2007). 
Time, effort and money are directed towards its diagnosis and treatment, but the resulting costs are high in financial terms and in human suffering (Williams et al 2007). While most back pain resolves quickly, in 20\% of cases it continues to be a problem (Deyo and Phillips 1996), especially in Western industrial societies, as it can be severely disabling and can reduce quality of life. Chronic pain is defined by the International Association for the Study of Pain (2007) as any pain that persists for at least 3 months and originates from a non-identifiable pathological condition, or a pathological condition that has not responded to traditional medical or surgical treatments.

Chronic low back pain is often the consequence of a workplace injury and can result in the loss of employment. Health professionals are increasingly involved in the management of work-related injuries and with people who are seeking employment. In Australia, changes to occupational health and safety legislation during the 1980s increased focus on the active rehabilitation of occupational injuries to help reduce disability and minimise societal and economic costs, and ultimately return the injured person to work (Deen et al 2002).

Most literature focuses on the biomedical diagnostic aspects and the efficacy of treatment regimens. In comparison, relatively little literature explores the pain experience from a qualitative perspective (Ashby et al 2010). Consequently, there is less published about the human experience of chronic low back pain, using people's words or story to describe its impacts. Indeed, there has been no specific discussion of its impact on the leisure lives of people.

This article describes a study that explored the impact of chronic low back pain on people's leisure lives, and the application of this information to occupational therapy. In the ethnography a person-centred perspective was used, which drew upon 'stories of illness' (Brody 1987). In occupational therapy, a person's story can illustrate the impact of injury or illness on occupational participation in the contexts of time and place (Wicks and Whiteford 2003). Stories provide researchers with a contextual framework to understand occupational experiences.

The study involved men with chronic low back pain who attended the Work Fitness Programme (WFP), a 1-year pilot work hardening programme funded by the Commonwealth Rehabilitation Service (CRS): an Australian Federal Government agency that provides vocational rehabilitation services. It was funded to evaluate the effectiveness of work hardening for people with chronic low back pain who were unemployed for more than 8 months. Work hardening is a treatment used as part of a vocational rehabilitation programme to return clients to work.

The WFP consisted of a work hardening component and an exercise programme that ran throughout the week. It comprised structured and graded tasks to increase a person's psychological, physical and emotional tolerance, and to improve endurance, general productivity and work feasibility (Schaafsma et al 2010). It also included three gymnasium sessions and daily walking groups. Participants attended for 6-8 weeks.
The findings in this paper came from a broader study that evaluated the effectiveness of the programme and included an ethnographic-style initial interview and conscious participant observation during daily interactions (Ashby 1999).

\section{Leisure}

Originating in sociology, the debates in occupational therapy about how to understand and define leisure focus on three main perspectives. The first perspective is leisure as time, which defines leisure as the time not spent in sleep, rest or paid employment. This definition allows the measurement of potential time spent in leisure, but does not focus on what activity a person engages in. The second perspective is leisure as activity and defines leisure as specific activities, with leisure interests identified using a checklist approach. This approach is problematic as it often reflects the checklist author's interests, social class, gender and cultural or ethnic background. People completing the checklist may be deterred from suggesting their own interests if they are not on the list.

The third perspective is leisure as a subjective experience, based on the work of Csikszentmihalyi (1991), whose research suggests that leisure cannot be defined as enjoyable or pleasurable because this ignores the fact that some work is pleasurable and some leisure activities are not (Primeau 2009). Thus each individual's experiences of leisure are unique and can change over time. Csikszentmihalyi's (1991) 'flow model' is based on the idea that a person's consciousness of self disappears as abilities match challenges and action merges with awareness. There is no attempt to classify an activity as leisure or work as it is the person's occupational experience that is important. It is the person's state of mind or consciousness at the time which determines if it is enjoyable. Hammell (2009) argued that exploration of a person's experiences best fits with occupational therapy as this increases understanding of the meaning a person attributes to an occupation. Other researchers have used this perspective to explore the contribution leisure plays in the wellness of community-living older people (Pereira and Stagnitti 2008).

The purposes of the evaluation were to discover the effectiveness of the programme in assisting people to return to work and to determine how occupational therapists might play a stronger role in enabling people to manage, and adapt to, chronic low back pain.

\section{Method}

Prior to the commencement of the study, and the programme, CRS Australia's research committee granted ethical approval. A written information sheet was provided to potential participants. They were also informed that the decision to proceed with the WFP was not dependent on the agreement to be included in the research component. Each participant signed and received a copy of the consent form, confirming their right to withdraw from the research component at any time.

Of the 16 people who attended the WFP, 11 met the criteria and agreed to participate. The criteria were that 
they had been unemployed for longer than 8 months and were not currently involved in any legislative action for their musculoskeletal injury. An ethnographic methodology was employed to collect the data because, through a range of research methods, ethnographies provide 'thick description through which meaningful structures may be identified and interpreted' (Geertz 1973, p390). This study employed participant observation, formal semi-structured interviews and informal ethnographic-style interviews (Spradley 1979).

Participant observation is the study of people by participating in social interactions to observe and understand them (Denzin and Lincoln 1994). Because of the first author's role as coordinator of the WFP and an occupational therapist, the type of participant observation used was participant as observer. Each day she observed the participants and interacted with them on a professional and personal level. These repeated face-to-face encounters helped her to develop an understanding of their perspectives about their lives, experiences and situations, as expressed by their words and actions (Minichiello and Kottler 2010). The goal was to create an informal element in her dealings with participants as opposed to a constant, more formalised, distancing structure. However, her position as a health professional in charge of the WFP and her gender required the retention of a level of formality.

The barriers to total informality were reduced through showing empathy and interest in the participants' problems. They regarded the first author as a person with whom they could discuss their lower back pain. As rapport was established the participants became more relaxed, talking about how their pain affected their lives. She used a client-centred approach to show that while she was an expert in her field, the participants were the experts about the effects of chronic low back pain on their lives.

Participant observation allowed her to verify the participants' interview responses and to ask more informal questions. Semi-structured interviews or open-ended ethnographic interviews explored the participants' perceptions of how pain had affected their lives in order to obtain the most informative answers. The use of interviews with participant observation is supported by Lofland and Lofland (1984).

Formal interviews were recorded with the participants' permission and transcribed verbatim. All identifying information was removed. Informal interviews and observations were recorded in field notes. Thus, the dataset included substantive notes, a transcript file, and personal and analytical logs (Minichiello et al 2008).

Reflexivity was a critical part of the analytical process. This included the use of an analytical log that provided new reflections on feelings, reactions, insights and interpretations about the data; the writing of the participants' stories; discussions with the second author and colleagues at WFP; and reflections related to their own life experiences, clinical experiences and backgrounds. The integral role of reflexivity and documentation in field notes formed part of the audit trail and enhanced the rigour and trustworthiness of the study (Padgett 2009). Data coding and thematic analyses were used as part of the reflective process
Table 1. Description of participants

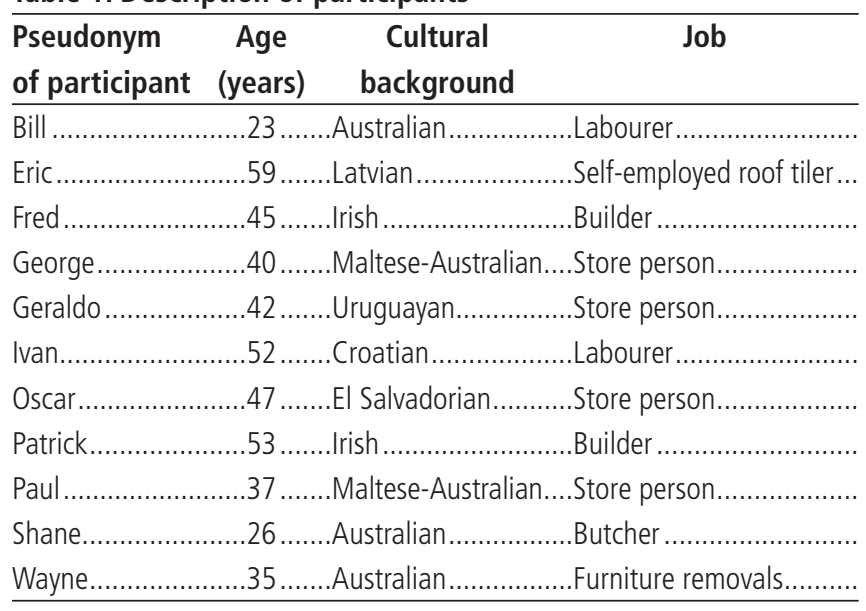

(Braun and Clarke 2006). This included the analyses of each person's data as well as across-group comparisons.

Narrative and life history approaches focus on the person and the meaning of experiences and events in the specific context of his or her life. They include the person's history and present information about his or her social, cultural and physical environment (Denzin and Lincoln 1994). Wicks and Whiteford (2003) argued that practitioners' use of narrative and life history as research methods can provide opportunities to understand what might otherwise remain an unspoken and informal part of therapeutic interactions. In this study, by listening to the participants' stories as they occurred as part of natural daily interactions, a fuller understanding of the meaning that the loss of work and leisure had for participants emerged. Thus, this daily talk was core data.

\section{Findings}

The 11 participants were men who had worked in blue-collar, semi-skilled or unskilled occupations. Prior to their low back pain, all were involved in work that required lifting and bending, such as a store person. Their length of unemployment ranged from 8 months to 7 years. Their ages ranged between 23 and 59 years. Three had an Australian cultural background and the other eight came from a European or South American background (Table 1). Disc involvement was a characteristic of all but one of the participants, who had scoliosis. In all other cases, it was chronic low back pain and subsequent reduction in function that caused the initial loss of employment and made finding new work difficult.

The focus of the ethnography was not on leisure, but the study revealed that leisure was far more important than anticipated. Each narrative was unique, but contained shared experiences of the loss of employment and leisure and 'Wayne's story' illustrates these main findings. This is the authors' version of 'Wayne's' story and provides a device for combining all sources of information about him into a format that highlights the reasons why people with chronic low back pain no longer engage in leisure. These include physical restrictions and financial barriers. 


\section{Wayne's story}

Wayne was a short, wiry man of 35 years from an AngloAustralian working-class family, a 'rough diamond' with love and hate tattooed on his knuckles. When I (first author) met him, he was at the end of his tether: despite his attempts to follow treatment advice, his low back pain had not improved.

For Wayne, independence was very important. He had left home and school at the age of 13 years and, since then, had worked all over Australia, trading his manual labour for a wage. His low back problems began 3 years earlier when he felt his back 'go' as he lifted a piano while working as a furniture remover. This 'came good' after he moved to the warmer climate of the Northern Territory, where he believed that this reduced his back pain. When he felt better, he moved back to work for his previous employer.

Unfortunately, another accident caused his pain to worsen. The X-rays showed a disc protrusion in the lumbar spine, but Wayne was certain his pain would improve as it had before. He had not claimed for Workers' Compensation because he wanted his old job back and knew it would prejudice his chances. A doctor told him that he could not go back to 'removals'. He knew that his work options were limited by his difficulty reading and writing and because he could no longer do manual work. Before his low back pain worsened, his literacy level was no barrier to getting a job. The change to his lifestyle made him feel depressed, but he did not discuss this with a doctor. Despite his tough appearance, Wayne cried as he told me his story and spoke of his fears and desperation to get better.

Like other participants, Wayne's whole life was affected by his low back pain, including his rest and leisure activities. Sitting was a 'killer' and often led to 'pins and needles' and numbness in his legs. He was unable to relax by watching the television because sitting in his easy chair was too uncomfortable. The pain affected his sleeping patterns because he could not rest in bed, and he had not slept well for 8 months.

When he talked about his past lifestyle and compared it with his present story, he cried again. In a year, he had lost everything that mattered to him: his job, his 'mates' and his sport. In his 'past story', he was a 'fit bloke' who played 'A' grade football and went out with his 'footie mates' for a drink after every game. He had worked and had socialised with workmates. When he worked, his life was organised into a routine and he was never at home. Now he was always alone because he had no money to go out and was physically unable to play sport again.

An important part of belonging to the football club was the after-game socialising. When unemployed, he refused the invitations of his sporting 'mates' to barbecues and parties at their homes as attending them was physically difficult. With no car and limited public transport he had to walk everywhere, but this 'hurt' his low back and standing or sitting were uncomfortable. Wayne could not afford to take any food or drink with him and he believed there was an unspoken rule that you brought beer for everyone. Instead of attending these social activities and explaining his financial and physical problems he avoided them, not wanting his 'mates' to know the extent that his low back pain had affected him.

To relieve his frustration and boredom, Wayne kept busy by doing his hydrotherapy exercises and enrolling in a parttime college course for 'industry catering' for restaurants. However, because of his poor literacy skills he had applied for the wrong course, one for prospective restaurant waiters which he did not want to be. His boredom and desire to do something meant that he continued to attend because it gave him something to do and he liked to keep busy. When he went there, he met other people and was not alone:

When I was working, I was never home; that's all changed for a while. I live on my own. I don't even have a girlfriend.

They don't want me when I have no money. I don't have anything now. You have to laugh, otherwise you might cry. I'm really fed up now. I really am.

He was worried about his future and needed to work to earn money:

There aren't other reasons why I want to go back to work. I just want money. I am bored but I'm only bored and fed up because I don't have any money. You can't do anything if you don't have any money.

Wayne came to the WFP to improve his physical fitness and because it filled his time with an activity. He most enjoyed attending the gymnasium. He discovered that he could do more activity and cope better with his low back pain. This was after I had explained that lifting within his functional abilities was not dangerous. At the end of the programme, he achieved his goal and found a kitchen-hand job at a local hospital.

In Wayne's story, there are constant references to social and leisure activities. Even his talk about productive occupations invariably connected to leisure. They were core factors in this version of his story and the way he talked about his life in everyday interactions with the first author and others involved in the programme. The same core theme was present in other participants' stories. Oscar talked about how his pain limited his participation in baseball and soccer; he did not even feel he could take on coaching the children's baseball team because he could not sit or stand long enough to watch them play. George's fear of reinjury kept him from going fishing alone. Terry loved working with his railway club, but stopped attending because he could not endure the drive there and he could not drive the steam trains or engage in other activities that the club members were expected to do when the railway was running. Like Wayne, Patrick and Bill, he no longer went to the pub to socialise with friends and find out about available jobs. They could not afford their own beer, let alone buy beers for their mates. Besides, standing for any length of time was too uncomfortable.

\section{Physical restrictions}

Physical restrictions reduced those activities that the participant was able to engage in due to reduced occupational performance. These included actual and perceived physical 
restrictions. Sports, such as baseball, rugby football and soccer, were not possible because of the physical requirements such as running and bending. However, for some leisure activities it was the fear of reinjury rather than actual restrictions that caused cessation. George had enjoyed going fishing alone but, since his injury, he would go only with his son. He said:

I mean anything could happen to me now; that's what makes me panic sometimes. I could be stuck down there, on the beach, unable to move ... That's what stops me from going more on my own. There's always that worry in my mind that something bad might happen to me ... I've experienced times when I couldn't move at all because of the pain.

\section{Financial restrictions}

Low back pain restricted all participants' working lives, which led to a loss of earnings. This blurred the boundaries between work and leisure. Without paid employment, the participants could not engage in leisure that required a financial contribution as often as when they were employed. Where social networking formed the basis for gaining work, loss of the leisure activity reduced work opportunities:

I've got just about every job through socialising ... looking for jobs in much more difficult (Patrick).

Being out of work ... has changed my life style. I can't go out and have a few beers with the boys like I used to. I stay at home most of the time. Before [the injury] I went out three or four times a week, now it's more like once a fortnight (Bill).

Fitzgerald (2000) suggested that people with hidden disabilities may choose not to disclose their disability as a way of preserving self-esteem. For participants in this study who did not disclose the restrictions of pain to others, it had a critical impact on their social networks. This was most severe for single men who were not able to discuss their problems, and who did not have a partner to support or encourage them to see other people:

It's hard to talk about it because I get so upset. So now I just stay at home and don't see any one. I lost contact with the people from work a long time ago. My wife is good; she makes sure we still see all the family. In a Maltese family that's quite a lot of people. I was never a drinking bloke, but now I don't even go down the club any more (George).

\section{Discussion}

The findings indicated that the illness experience of chronic low back pain affects all the occupational domains of a person's life and that they are connected. The major impact was on the ability to earn an income and to participate in leisure activities and thus engage in social networks. The main barriers to leisure were physical and financial restrictions. To overcome these, occupational therapists need to include a format that provides opportunities to listen to, and acknowledge, the critical impact that loss of leisure may have on a client's life.
Understanding the significance of loss provides a starting point for the discussion of new leisure activities. The techniques for eliciting information about a person's experiences of low back pain can be achieved in scheduled contact time with clients. These findings support the use of life history and narrative analysis as these techniques provide foundational information about a client and the study of occupational engagement and participation.

The findings also support listening to the client's story to understand how people with low back pain may set boundaries of fear avoidance for engaging in physically demanding work and leisure activities. Prior to engagement in work hardening, the participants appeared to set these boundaries based on their fear of reinjury, with an underlying concern regarding a fear of movement or kinesiophobia (Vlaeyen and Linton 2000). This is a common restriction for people with chronic low back pain, which potentially reduces their engagement in all activities (Ashby et al 2010).

Occupational therapists providing services for clients whose occupational choices are limited by kinesiophobia can employ skills in occupational analysis to provide tailor-made education and re-engagement interventions to overcome these fears. This allows clients to develop other areas of leisure that can assist in maintaining social networks and sustaining subjective wellbeing (Doble and Santha 2008). Engagement in graded return to work activities, either in the workplace or through work hardening programmes, can assist in improving a level of function that allows re-engagement in the workforce (Williams et al 2007). This may also allow them to engage in leisure. Occupational therapists may encourage clients to tell others about their restrictions rather than losing the social networks created through participation in leisure and work. The maintenance of leisure is important because it is one method by which working-class men construct their identity (Unruh 2004).

The findings demonstrate how social class and financial restrictions play a critical role in occupational engagement for people with chronic low back pain who are unemployed (Beagan 2007). An ethnographic methodology provides rich data, but the generalisability of the findings is restricted by the small sample. An additional limitation was that all the participants were working-class men. Although the findings demonstrate that there are common restrictions created by chronic low back pain, further research is necessary to determine if they cross gender and social classes. In addition, the techniques used by occupational therapists for leisure re-engagement require further exploration.

\section{Conclusion}

Leisure plays an important part in defining an individual as a unique occupational being. With chronic low back pain's potential critical impact on all aspects of a person's leisure, occupational therapists are in a position to overcome these through assisting in re-engagement and participation in leisure activities. Practitioners can support a client's disclosure of 
limitations to others, and identify alternative leisure activities that enable the maintenance of roles and social networks. To understand better a client's experience of low back pain and occupational needs, practitioners need to give attention to the everyday talk of their clients, their narratives, as a means of developing meaningful ways of addressing all occupational domains.

Conflict of interest: None declared.

\section{Key findings}

- Loss of leisure impacts on social networks and on occupational identity.

- Practitioners can play a role in enabling re-engagement in leisure through education and re-engagement interventions to overcome kinesiophobia.

\section{What the study has added}

Occupational therapists need to give attention to narratives to understand the impact of chronic low back pain in order to develop meaningful ways of addressing all occupational domains.

\section{References}

Ashby SE (1999) How low back pain affects lives: listening to people's pain stories. Unpublished thesis, Master's in Applied Science by Research. Sydney: University of Sydney.

Ashby S, Richards K, James C (2010) The effect of fear of movement on the lives of people with chronic low back pain ... including commentary by Carleton RN, Poulain C, Meyer K, Glombiewski JA. International Journal of Therapy and Rehabilitation, 17(5), 232-43.

Beagan BL (2007) Experiences of social class: learning from occupational therapy students. Canadian Journal of Occupational Therapy, 74(2), 125-33.

Braun V, Clarke V (2006) Using thematic analysis in psychology. Qualitative Research in Psychology, 3(2), 77-101.

Brody H (1987) Stories of sickness. New Haven: Yale University Press.

Chapparo C, Ranka J (1997) Occupational performance model (Australia): Monograph 1. Sydney: OP Network.

Csikszentmihalyi M (1991) Flow - the psychology of optimal experience. New York: Harper Collins.

De Souza LH, Frank AO (2007) Experiences of living with chronic back pain: the physical disabilities. Disability and Rehabilitation, 29(7), 587-96.

Deen M, Gibson L, Strong J (2002) A survey of occupational therapy in Australian work practice. Work, 19(3), 219-30.

Denzin N, Lincoln YS (1994) Handbook of qualitative research. Thousand Oaks, CA: Sage.

Deyo R, Phillips WR (1996) Low back pain: a primary care challenge. Spine, $21(24), 2826-32$.

Doble S, Santha J (2008) Occupational well-being: rethinking occupational therapy outcomes. Canadian Journal of Occupational Therapy, 75(3), 184-90.
Fitzgerald MH (2000) 'You look so well': the multiple facets of hidden disabilities. Society for Disability Studies Quarterly, 20(3), 254-58.

Geertz C (1973) The interpretation of cultures: selected essays. New York: Basic Books.

Hammell K (2009) Self-care, productivity, and leisure, or dimensions of occupational experience? Rethinking occupational 'categories'. Canadian Journal of Occupational Therapy, 76(2), 107-14.

International Association for the Study of Pain (2007) IASP pain terminology. Available at: $h t t p: / / w w w$.iasp-ain.org/AM/Template.cfm?Section=Pain Definitions\&Template=/CM/HTMLDisplay. cfm\&ContentID=1728\#Pain Accessed 03.11.08.

Lofland J, Lofland L (1984) Analyzing social settings. Belmont, CA: Wadsworth. Minichiello V, Kottler JA, eds (2010) Qualitative journeys: student and mentor experiences with research. Thousand Oaks, CA: Sage.

Minichiello V, Aroni R, Hays TN (2008) In-depth interviewing: principles, techniques, analysis. Frenchs Forest, NSW: Pearson Education Australia.

Padgett D (2009) Qualitative and mixed methods in social work knowledge development. Social Work, 54(2), 101-05.

Pereira RB, Stagnitti K (2008) The meaning of leisure for well-elderly Italians in an Australian community: implications for occupational therapy. Australian Occupational Therapy Journal, 55(1), 39-46.

Picavet HS, Vlaeyen JW, Schouten JS (2002) Pain catastrophizing and kinesiophobia: predictors of chronic low back pain. American Journal of Epidemiology, 156(11), 1028-34.

Primeau L (2009) Play and leisure. In: E Blesedell Crepeau, E Cohn, BA Schell, eds. Willard and Spackman's occupational therapy. 11th ed. Philadelphia, PA: Wolters Kluwer/Lippincott Williams and Wilkins, 633-49.

Rebeiro KL, Polgar JM (1999) Enabling occupational performance: optimal experiences in therapy. Canadian Journal of Occupational Therapy, $66(1), 14-22$.

Schaafsma F, Schonstein E, Whelan K, Ulvestad E, Kenny D, Verbeek J (2010) Physical conditioning programs for improving work outcomes in workers with back pain. Cochrane Database of Systematic Reviews, Issue 1. Art. No.: CD001822.

Spradley JP (1979) The ethnographic interview. Orlando, FL: Holt, Rinehart and Winston.

Unruh AM (2004) Reflections on: 'So ... what do you do?' Occupation and the construction of identity. Canadian Journal of Occupational Therapy, 71(5), 290-95.

Vlaeyen JW, Linton SJ (2000) Fear-avoidance and its consequences in chronic musculoskeletal pain: a state of the art. Pain, 85(3), 317-32.

Wicks A, Whiteford G (2003) Value of life stories in occupation-based research. Australian Occupational Therapy Journal, 50(2), 86-91.

Williams RM, Westmorland MG, Lin CA, Schmuck G, Creen M (2007) Effectiveness of workplace rehabilitation interventions in the treatment of work-related low back pain: a systematic review. Disability and Rehabilitation, 29(8), 607-24.

Zemke R, Clark F (1996) Occupational science: the evolving discipline. Philadelphia: FA Davis 